\title{
A compreensão de mães sobre os serviços do programa saúde da criança
}

\author{
Dennis Soares LEITE(1) \\ Perla Suely Gaia Ranieri QUEIROZ ${ }^{(1)}$ \\ André Luís QUEIROZ ${ }^{(1)}$ \\ Ingrid Magali de Souza PIMENTEL ${ }^{(1)}$
}

Recebido: 28 jan 2019

Aceito: 10 fev 2019

Autor de

correspondência:

dennissoares7@gmail.com

Conflito de interesses: Os autores declaram não haver nenhum interesse profissional ou pessoal que possa gerar conflito de interesses em relação a este manuscrito.
${ }^{(1)}$ Universidade de São Paulo - USP, São Paulo, SP, Brasil.

\section{Resumo}

A saúde da criança representa um campo prioritário dentro dos cuidados à saúde das populações. Para que essa se desenvolva de forma mais efetiva e eficiente, além do conhecimento sobre as características relacionadas à morbimortalidade, tais como aspectos biológicos, demográficos e socioeconômicos, é importante salientar o papel que desempenham os serviços e o sistema de saúde. Problemas no cumprimento de normas técnicas por parte dos profissionais, no relacionamento entre profissional paciente e familiares, falta de equipamentos e outros insumos, deficiências na notificação de dados e dificuldades no processo de trabalho dos profissionais, são aspectos decisivos para uma adequada atenção à saúde. Dessa forma, a pesquisa tem o objetivo de conhecer a compreensão de mães sobre os serviços oferecidos pelo programa saúde da criança visando à construção de uma tecnologia educativa. Trata-se de uma pesquisa de campo, exploratória, de natureza aplicada, com abordagem qualitativa com a utilização de uma entrevista semi-estruturada. A pesquisa foi realizada na Unidade Básica de Saúde Cidade Nova VI (UBS CN VI), situada na Cidade Nova VI (CN VI), em Ananindeua no Estado do Pará. A pesquisa foi aprovada pelo Comitê de Ética em Pesquisa da Fundação Santa Casa de Misericórdia do Pará sob o número CAAE: 53934016.9.0000.5171. Participaram da pesquisa 20 mães que assinaram o Termo de Consentimento Livre e Esclarecido e realizaram acompanhamento pré-natal na UBS CN VI no ano de 2016 e que retornaram à unidade juntamente com seus bebês para realização de consulta médica e ou de enfermagem visando o acompanhamento do crescimento e desenvolvimento infantil. Como critério de seleção da amostra foi utilizado o critério de saturação das informações. A obtenção dos dados foi realizada no período de junho a agosto de 2016 durante a consulta de enfermagem. "Não sei muito bem o que é, mas deve ser algum programa de prevenção, alguma coisa de cuidado com a criança pequena. "É saúde para nossos filhos, ajuda a evitar certas doença [sic] porque a gente tem que cuidar bem das criança como falam para gente nas consultas do posto!". As falas demonstram que as mães exaltam a relevância dos atendimentos previstos pelo programa saúde da criança na condução dos cuidados a essa fase da vida. As mães acreditam que ao realizarem as ações do programa estão efetivamente 
cuidando da saúde dos bebês. "Eu tenho muitas dúvidas sobre os atendimento [sic] no posto, sobre as vacinas quando a gente tem que fazer, os exames que a criança tem que fazer. Sabe como é né, é difícil para nós gravar todas aquelas datas das vacinas". "Tenho bastante dúvidas porque é o meu primeiro filho. Eu tenho dúvidas sobre as vacinas se a criança pode fazer quando está doente". "Período ideal? Sei o que fica marcado na carteira, como por exemplo as vacinas, o resto eu não sei não. Os exames eu sei que tem período melhor para fazer, mas não sei direito quando é". O cuidado prestado à criança tem o propósito de promoção de saúde através de ações prioritárias de vigilância e do acompanhamento do crescimento e do desenvolvimento infantil. Por isso, é fundamental que a família seja cercada de todas as condições necessárias para a prestação do cuidado. Nessa perspectiva, observamos que diversos fatores contribuem para que os cuidados pertinentes à atenção integral à criança não sejam realizados da forma como são preconizados. Ficou evidente que todas as mães entrevistadas apresentavam conhecimento sobre o programa e que o relacionavam ao cuidado com a saúde dos bebês por meio da realização de uma série de serviços. As mães ressaltaram dentre desses cuidados os seguintes serviços: imunização, consultas, aleitamento materno exclusivo e exames com destaque para o teste do pezinho, o teste do reflexo vermelho e a triagem auditiva neonatal. Também ressaltaram que esses cuidados têm importante função preventiva colaborando para a manutenção da saúde infantil. Ficou notório, que existem barreiras de comunicação entre os profissionais de saúde e as mães e que o baixo nível de escolaridade é um fator que tem importante contribuição para o aumento desses obstáculos. A despeito das estratégias citadas pelas mães para o cumprimento das ações do programa, uma minoria das mulheres referiu que aguardava as consultas na tentativa de buscar esclarecimento de dúvidas sobre quando e quais serviços deveriam ser realizados. Ainda assim, devemos ressaltar que muitos profissionais realizam consultas rápidas focalizando o atendimento apenas na doença e dessa forma perdem a oportunidade de fornecer informações relevantes às mães durante as consultas ou visitas domiciliares deixando essas mulheres em uma atmosfera de dúvidas cuja tendência é só aumentar caso não sejam esclarecidas corretamente. Ainda no tocante as dúvidas das mães, muitas entrevistadas relataram que o excesso de informações e serviços do programa acaba sendo um fator que dificulta a compreensão, memorização e a realização dos serviços. Esses dados apontam que o profissional de saúde deve criar mecanismos que favoreçam a aprendizagem e esses mecanismos devem acompanhar as novas tecnologias em saúde visando alcançar resultados positivos na melhor compreensão e adesão das mães no atendimento da criança conforme o preconizado pelo Ministério da Saúde. É fundamental ainda, que os profissionais de saúde utilizem e valorizem os instrumentos de monitoramento em saúde existentes, dentre os quais destacamos a caderneta de saúde da criança. É essencial também, que esses profissionais, em especial o enfermeiro, utilizem ferramentas pedagógicas que privilegiem as mães como protagonistas no processo de construção do cuidado. 
É necessário que esses profissionais desenvolvam novas formas de educação em saúde que se tornem mais interessantes aos usuários, como por exemplo as novas tecnologias de educação em saúde das quais destacamos as rodas de conversa, os jogos educativos e os aplicativos de celular. Metodologias pedagógicas que rompam com o padrão biomédico e que estejam em consonância com o mundo contemporâneo que traz o paciente como personagem principal do novo modelo de saúde.

Descritores: Sistema Único de Saúde; Política de Saúde; Educação em Saúde. 